\title{
Studying Technology Adoption Inhibition in the Context of Food Ordering Apps
}

Easwar Krishna Iyer*, Anchit Gujral†, Anuja Raundal $¥$, Hardik Saxena§

\section{Abstract}

Food ordering apps are dramatically changing the out-ofhome food consumption. With mobile phones emerging as the ubiquitous self-help device, a new wave of food ordering is evolving. This study aims at identifying the technology adoption inhibitors that consumers face when they migrate from dine-out experience to online takehome experience. We propose insecurity, discomfort, infrastructure and inertia as four inhibitors for a full-scale migration to online food ordering and establish that all four variables are significant in explaining the current consumer inhibition in the area of the study mentioned. While adoption, acceptance and readiness for technology usage are given attention and focus, this study stands out as an analysis of consumer inhibition patterns.

Keywords: Technology adoption model, Inhibitors, Insecurity, Discomfort, Infrastructure, Inertia, Food ordering apps

\section{Introduction}

Technology has enhanced the ease with which people procure both goods and services. With mobile phones emerging as the ubiquitous last mile device, a plethora of Self-Service Technologies

* Great Lakes Institute of Management (GLIM), Chennai, India; easwar@greatlakes.edu.in

† GLIM, anchit.pgpm18c@greatlakes.edu.in

执 GLIM, anuja.pgpm18c@greatlakes.edu.in

\$ GLIM, hardik.pgpm18c@greatlakes.edu.in 
(SST) have emerged to facilitate the easier fulfillment of needs at the mere press of a button. As a two-way communication tool, mobile phones are rapidly changing the way. Self-Service Technologies are created, developed and delivered to users. A real consolidation of these SSTs will happen only when businesses understand and overcome the inhibitors that the individual consumers have in adopting these technologies. For ensuring the large-scale acceptance of SSTs, one needs to study the technology inhibition landscape of consumers. Negative valence (inhibitors) is always stronger than positive valence (drivers) in any adoption scenario (Iyer et al., 2015). This study aims at mapping the inhibitor landscape of consumers in the context of Food Ordering Apps.

The area of mobile commerce or m-commerce can be considered as both a subset and an enhancement of the broader area of ecommerce. As a platform, m-commerce has today made major inroads into shopping, ticketing and financial transactions. Techsavvy millennials use mobile applications more than traditional websites to connect to e-tail platforms. Because of this changing consumer behaviour, businesses are also developing mobile-based platforms as a more acceptable substitute for traditional websites (Wakefield \& Whitten, 2006). The food delivery industry is the latest to join the technology bandwagon in integrating mobile phone applications into their last mile supply chain. The use of mobile phone as an SST tool in the food ordering process gives consumers a sense of control over the pace of transaction with the service provider. This increased sense of control leads to a higher level of customer satisfaction (Durkin, 2004). Studies are being perused today to understand consumer attitudes in the context of choice between interpersonal services and SST (Dabholkar, 1995).

In the food ordering space, mobile commerce can be construed as the consequence of consumers availing ubiquitous Self-Service Technology to save time and the effort of moving out and dining. However, the acceptance of the new medium of purchasing is contingent on understanding both motivators and inhibitors to technology adoption. Motivators prompt consumers to adopt SST, thus ordering food via online apps. On the other hand, inhibitors contribute to the pre-existing reluctance in the consumers' minds in the context of adopting any new technology. The opposing forces 
in any decision making can cause the customer to be in a state of flux. The final acceptance and adoption of Self-Service Technology are thus contingent on inhibition of amelioration.

This study focusses on the inhibitors to technology adoption. The study aims to identify the various inhibitors that consumers face while ordering food via online apps when they are migrating from a traditional dining out format to an online home delivery format. The intention of the study is to propose a set of qualifiable inhibitors in the context of mobile app-based food ordering and then measure and validate their relative importance. This study can eventually be used to model consumer inhibition behaviour across various SST platforms. Before the methodology, results and discussions of the study are enumerated, a brief literature survey of the proposed variables is offered.

\section{Literature survey}

This section pans through existing literature on Technology Adoption Model (TAM) followed by a brief literature overview of each of the four proposed inhibitor variables. The Technology Adoption Model (Davis, 1989) delves into consumer insights prior to the adoption and acceptance of the technology. The Davis study proposes Perceived Usefulness (PU) and Perceived Ease of Use (PEU) as the two variables that drive the adoption of any technology. PU describes the degree by which consumers perceive technology as a performance enhancement tool whereas PEU describes the degree by which consumers perceive effort in the context of technology adoption. The TAM model has been extensively used by subsequent researchers in specific adoption contexts.

Even prior to TAM, consumer beliefs, intentions and attitudes have been studied by Fishbein and Ajzen (1975) in their Theory of Reasoned Action (TRA) framework. The TAM model was followed by the Technology Readiness Index (TRI) model (Parasuraman, 2000) which moves the focus of interest from technology to adopters. TRI explores an individual's mental state of being ready for technology acceptance and is one of the first models to study drivers in conjunction with inhibitors. With TAM, TRA and TRI 
offering a backdrop, we will now pan through literature that deals with the four proposed study variables.

\subsection{Insecurity}

Insecurity is one of the earliest proposed technology inhibitors in literature and is defined as a lack of trust in technology and its ability to work properly (Parasuraman, 2000). A perceived sense of insecurity is what has contributed to the initial scepticism for ecommerce adoption (Hoffman et al., 1999). In the specific context of online food ordering, Schnellbächer et al. (2015) assert that convenience and time savings are factors affecting the decision of online ordering. Their study mentions that non-users refrain from the use of SST mainly due to the perceived lack of skills required for the online platform. This consumer behaviour can be closely approximated to the Parasuraman definition of Insecurity.

\subsection{Discomfort}

The inhibitor variable called Discomfort is described as the perceived lack of control and a feeling of being overwhelmed by technology (Parasuraman, 2000). Meuter et al. (2003) demonstrate that technology anxiety has a strong negative effect on customer adoption and customer experience in the context of SSTs. Technology Readiness Index (TRI) is the overall mental gestalt that includes positive (optimism and innovativeness) and negative (discomfort and insecurity) feelings when consumers interact with technology. In the context of an SST acceptance, such a bivalent behaviour has been analysed by Chris et al. (2006). Discomfort and its impact on SST acceptance have been studied by Meuter et al. (2003) and Dabholkar and Spaid (2012) where the consumer's attitude, ability, and willingness to adopt is modulated by the amount of comfort that he has while using technology.

\subsection{Infrastructure}

While Insecurity, Discomfort and Inertia are soft and intangible behavioural inhibitors, Infrastructure deals with the tangible technological elements whose presence or absence can have a significant say in the adoption behaviour of consumers. As an example, the infrastructural character of the Internet will have a significant say in the attitude and intention to use of technology 
systems where the Internet is the mainstay (Shih \& Fang, 2006). The main characteristic of infrastructure is that it is a part of the overall capital stock which is important for the subsistence of general purpose technologies (GPTs) which include SSTs. The implicit uncertainty around on-line transactions driven by the unpredictability of internet infrastructure is discussed by Brynjolfsson and Smith (2000).

Lee (1998) studies the susceptibility of consumers to incomplete or distorted information because of their reliance on electronic infrastructure. The risk of privacy associated with sharing personal information over the web is studied by Culnan and Armstrong (1999). Meuter et al. (2000) have deduced that the frequency of technical issues and concomitant downtime cause consumers to switch service providers. Finally, Hoffman et al., (1999) have studied the open nature of the Internet as a transaction infrastructure and the uncertainty that it creates around online transactions. Continuing on Infrastructure, Dabholkar (1995) has established that reliability and accuracy of online purchasing is an important factor to consider while evaluating the adoption of SelfService Technology. The same is directly related to the perceived performance of the technology backbone. In a related study, Dabholkar and Spaid (2012) have concluded that service failure has a negative impact on user satisfaction in the e-world and any attempt towards failure reduction will significantly reduce the original negative impact and raise customer satisfaction.

\subsection{Inertia}

Several theories in psychology address the consumer's resistance to change from the status quo (Osgood \& Tannenbaum, 1955). These studies have concluded that any change in established routines can potentially disturb the consumer's psychological equilibrium thereby inducing a buying resistance. This phenomenon is known as Inertia. Adoption failure due to user resistance appears in a number of cases. Inertia refers to maintaining the status quo in the face of pressure to change and is concerned with how consumers feel threatened about change. As an example, adoption to the mobile app service can be promoted only when inertia is moderated (Hyunsuk et al., 2014). 
In the context of adoption resistance due to inertia, it has been observed that any relative advantage can reduce resistance to innovation whereas any perceived complexity can increase resistance (Ram, 1987). Joseph (2010) has established that when adopting the personal computer, technological complexity negatively influences the intention to adopt. Resistance to adopting new technologies has also been validated in other contexts such as internet banking and mobile banking (Laukkanen et al., 2007).

\section{Method}

The study aims at finding out the significant variables that trigger inhibition behaviour for technology adoption in the specific context of usage of Food Ordering apps. The study proposes Insecurity, Discomfort, Infrastructure and Inertia as the four variables that could act as potential inhibitors to adoption. The methodology proposed for arriving at the research conclusions is Confirmatory Factor Analysis followed by Regression. The survey is administered through an online questionnaire which was developed and delivered through the Qualtrics platform. Since the research is exploratory in nature, we have adopted the convenience sampling technique. The respondents were qualified as 'Mobile App Persons' (people who use mobile phones and are conversant with the usage of Mobile Apps) and their selection was done based on their convenient accessibility and proximity to the researchers. Despite the qualification of the respondent population as mobile savvy and app conversant, there is still a fair assumption that the respondents are conversant with the mobile-driven Food Ordering App market and most, if not all of them have used this service at some point or the other.

A total of 136 respondents completed the administered online questionnaire. The questionnaire was sent to respondents who are from Tier-I \& Tier-II cities in India. The respondent sample had more men $(52.5 \%)$ than women $(47.5 \%)$. The largest group of respondents was between the ages of 18 and 30 years (43.3\%). The average age of the respondent population is 27 years. For earning respondents, the income distribution ranged from a monthly income of INR 10,000 to 60,000 . There were also substantial respondents who are currently not earning (24.2\%). The sample 
population of the respondents was found to be majorly from the salaried class $(43.3 \%)$. Overall, the sample is young and appears to be earning more compared to the current national population. Note that though our sample may not be representative, the target population of online survey participants was purposely selected to meet the needs of this study, as discussed previously.

After eliminating responses which were either incomplete or has the same rank scale for all questions (i.e. standard deviation of the respondent across all scales was 0.0 ), the final run of the study had 120 complete responses. A five-point Likert scale ranging from 'Strongly Agree' to 'Strongly Disagree' has been used with the option of a neutral/undecided stand in between to measure the responses. IBM SPSS Statistics 20.0 was used for data analysis. Confirmatory Factor Analysis (CFA) was done with the forced option of throwing 4 factors since the study starts with 4 proposed variables. The factors have been extracted using Principal Component Analysis. Varimax Rotation has been applied to ensure that no attribute loads more than a single factor. The factors that emerged were converted into variables and the Regression was done on the emerged Factor Variables. The results obtained for both CFA and Regression and its analysis is presented in the next section.

\section{Results and analysis}

Before we get into the actual results, the research background for this study is restated. Based on the original nomological structure proposed by Davis (1989) for Technology Adoption Modelling (TAM), this study proposes a technology inhibition model that integrates a set of four beliefs - all drawn from literature - on what could probably inhibit consumers from adopting technology. The four variables proposed after intensive literature study are Insecurity, Discomfort, Infrastructure and Inertia and the industry of observation for this study is the online food-ordering app industry. 


\begin{tabular}{|c|c|c|c|c|}
\hline \multicolumn{5}{|c|}{ Rotated Component Matrix* } \\
\hline & \multicolumn{4}{|c|}{ Component } \\
\hline & Insecurity & Infrastructure & Inertia & Discomfort \\
\hline Insecutiry2 & .705 & & & \\
\hline Insecutiry3 & .0832 & & & \\
\hline Insecutiry4 & .0839 & & & \\
\hline Insecutiry5 & 0794 & & & \\
\hline Infrastructure1 & & .863 & & \\
\hline Infrastructure2 & & .898 & & \\
\hline Infrastructure3 & & .754 & & \\
\hline Inertia1 & & & .751 & \\
\hline Inertia2 & & & .801 & \\
\hline Inertia3 & & & .870 & \\
\hline Discomfort1 & & & & .795 \\
\hline Discomfort2 & & & & .863 \\
\hline Discomfort3 & & & & .489 \\
\hline CA & 0.876 & 0.868 & 0.812 & 0.718 \\
\hline Factor-vice Variance & $21.22 \%$ & $19.47 \%$ & $18.07 \%$ & $13.33 \%$ \\
\hline Total Variance & $72.091 \%(>50 \%)$ & & & \\
\hline Extraction Method & \multicolumn{4}{|c|}{ Principal Component analysis } \\
\hline Rotation Method & \multicolumn{4}{|c|}{ Varimax with Kaisset Normalization (Rotation converged in 5 iterations) } \\
\hline Bartlett's Sphericity & \multicolumn{4}{|c|}{ Approx. Chi-Square $=815.083[\mathrm{df}=78 ;$ Sig. $=0.000]$} \\
\hline CA & Cronbach Alpha & & & \\
\hline
\end{tabular}

Fig 1 Principal Component Analysis with Varimax Rotation

The Food Ordering App industry falls under the broad category of Self-Service Technology (SST) where consumers themselves produce services without interacting with a direct service employee. With most face-to-face purchases having an online option today, it makes a lot of sense to study the ecosystem of technology-driven self-service models. The results that are enumerated below offer a basic perspective of determining the resistance points of consumers in their quest for using Food Ordering Apps. This research study, as will be seen from the nature of its outputs, aims at providing a basic model that can predict the reticence/inhibition / tardiness of consumers in using technology for realising a service without any direct human intervention. The details of the Principal Component Analysis which delineate the four factors under consideration are shown in Figure 01.

The Confirmatory Factor Analysis throws up the 4 proposed factors without any cross loading. The Cronbach Alpha for the 4 scales ranges from 0.718 to 0.876 , indicating good internal consistency for all the scales proposed. The study had 5 scale items for Insecurity and 3 each for the remaining three variables. After pilot studies, 
one of the scale items of Insecurity (Insecurity 1) was removed to improve Cronbach Alpha. All the remaining proposed scales are used in the final study. The scales used in the study are given as Appendix 01. The Kaiser-Meyer-Olkin measure for sampling adequacy is 0.822 and Bartlett's Test of Sphericity yields an approximate Chi-square value of 815.083. Both values indicate the appropriateness of the factor analysis approach. The total variance explained by the 4 factors is $72 \%$ with the 4 emerging factors explaining $21 \%, 19 \%, 18 \%$ and $13 \%$ of the variance. Thus, no factor significantly overrides the others in terms of relative importance in explaining the observed behaviour. The rotation method used is the Varimax rotation method and the results are found to converge within 5 iterations.

The dependent variable for the study is phrased as 'I am happy with ordering food via phone call and do not wish to switch to mobile apps'. By its very nature of phrasing, the scenario moves away from dining out experience and compares procuring/ordering of food via phone calls vis-à-vis via mobile apps. This ensures that the inhibitors that are thrown up are only related to the usage or non-usage of Mobile Apps for an eat-athome dining experience. Since we are primarily measuring only the inhibitor landscape which is not a $360^{\circ}$ coverage of consumer expectations, the observed $\mathrm{R}^{2}$ value of 0.378 is adequate. The $\mathrm{F}$ value of the ANOVA test is 17.5 with the significance of 0.000 indicating the robustness of the results. All the 4 proposed factors of the study emerge as significant while the highest beta coefficient emerges for the Inertia Factor.

\begin{tabular}{|c|c|c|c|c|c|}
\hline \multicolumn{6}{|c|}{ Predictor Variables and Regression Coefficients [For n=120] } \\
\hline Predictor & Unstandard & & Standardized & $\mathrm{T}$ & Significance at \\
\hline Variables & Coefficients an & Error & Coefficients & & 95\% Confidence \\
\hline (Constant) & 3.008 & .098 & - & 30.713 & .000 \\
\hline Insecurity & .437 & .098 & .326 & 4.438 & .000 \\
\hline Infrastructure & .269 & .098 & .201 & 2.734 & .007 \\
\hline Inertia & 0597 & .098 & .446 & $6 . .069$ & .000 \\
\hline Discomfort & .241 & .098 & .180 & 2.449 & .016 \\
\hline $\begin{array}{l}\text { Dependant } \\
\text { Variable }\end{array}$ & \multicolumn{5}{|c|}{$\begin{array}{l}\text { I am happy with ordering food via phone call and do not wish to switch to } \\
\text { mobile apps }\end{array}$} \\
\hline R Square & \multicolumn{5}{|c|}{0.378} \\
\hline F Value & \multicolumn{5}{|l|}{17.5} \\
\hline Significance & \multicolumn{5}{|l|}{0.000} \\
\hline
\end{tabular}

Fig 2 Predicator Variables and Regression Coefficients 
Regression is performed using the 4 emerged factors to find out the significant factors that drive the inhibition spectrum for Food Order App adoption. The Predictive Variables and their Regression Coefficients are mapped in Figure 02.

The significance for all the proposed Inhibitor factors indicates that Inhibition is a relevant area of study for nascent emerging technologies. The understanding that is derived about these inhibitors will help along three vectors. App service vendors will ensure that they develop and deliver Apps that have a robust technology. Care will be taken to reduce any sense of discomfort for the customer and finally any innate sense of insecurity for the user in his interaction with technology will be played down. All these measures will cumulatively help in easing out the inertia that the market has in switching from status quo usage platforms to new age App based platforms. A closer understanding of the consumer mindset will go a long way in helping the nascent Food Ordering App via technology to gain larger market traction.

\section{Conclusion}

Most of the technology that is regularly used today did not exist twenty-five years back. Personal computing entered work spaces only by the early 1990s. Mobile telephony and the Internet were born a few more years later in 1995. The turn of the millennium saw the market getting flooded with laptops with the early versions being bulky and cumbersome to handle. Just about 10 years back there were no smartphones, no Cloud Computing as we know it today, no connected intelligent devices and most importantly no Social Media. LinkedIn was launched in 2003; Facebook in 2004 and Tweets were born through Twitter in 2006. The first version of iPhone was launched in 2007 and iPad hit the market in 2010. Thus, today's technology-deluged world is a fairly nascent world.

With a host of technology devices and solutions permeating homes and offices, there is a huge imperative to study the willingness, both at the individual level and at the institutional level, to accept and adopt technology. Explaining and predicting technology adoption has a rich academic history with the earliest model dating 
back to 1989. In this context, acceptance models have developed along two independent vectors. Some studies are system-specific and relate to the adoption of a specific technology (Davis, 1989) while others are individual-specific and focus on customer beliefs and their readiness for technology acceptance (Parasuraman, 2000). Most of these studies dwell on the utility-based drivers for technology adoption. This study moves the locus of attention from adoption to inhibition.

Resistance to anything innovative, particularly technology, is nothing new. It dates back to the 19th century when the Luddite movement acted as a social counterforce to industrial revolution in the United Kingdom. 'Luddism' exists even today but does not manifest itself by rioting and destroying machines. The suave 21st century Luddite opts for passive non-adoption. This study aims at understanding and mapping the hurdles to adoption by studying the inhibition spectrum.

The central premise of this paper is that inhibitor mapping, measurement and reduction should be an inherent part of the product development and 'go-to-market' strategy for any technology based product. The possibility of user acceptance of any technology can only be enhanced when one gains a keener insight into why users reject. Any nascent offering in the market will morph into an accepted offering only after the inhibitors associated with the product usage are mapped, measured and reduced. The paper does this mapping and measurement of customer inhibition in the context of Food Ordering Apps. The Confirmatory Factor Analysis results followed by the Regression firmly establishes the significance of all the four proposed inhibitor variables. This study is thus a good starting point for further researchers to develop detailed technology inhibition models that will effectively complement the existing technology adoption models.

\section{Limitations of the research}

The list of inhibitors in the cognitive and affective domain that will hinder the effective usage of technology is not restricted to the four inhibitors proposed in this study. The study has chosen four of the most relevant inhibitors in the specific context of the industry of 
observation (Food Ordering Apps). Inhibitors like Risk, Dissatisfaction, Disadoption, Dissonance, Distrust and Incompatibility can be modelled and studied in the context of various technologies. Also, some of the proposed variables can have a mediating effect which has not been analysed in this study. For the number of variables that are studied, the final sample size of 120 is adequate. But once the variables under study increase, a higher sample size will be needed for more accurate results.

\section{References}

Brynjolfsson, E., \& Smith, M. (2000). Frictionless commerce? A comparison of Internet and conventional retailers. Management Science, 46(4), 563585

Lin, C., Jiun-Sheng, \& Hsieh, P. (2006). The role of technology readiness in customers' perception and adoption of self-service technologies. International Journal of Service Industry Management, 17(5), 497-517.

Culnan, M.J., \& Armstrong, P.K. (1999). Information privacy concerns, procedural fairness, and impersonal trust: an empirical investigation. Organization Science, 10(1), 104-115.

Dabholkar, P. A. (1995). Consumer evaluations of new technology-based self-service options: an investigation of alternative models of service quality. International Journal of Research in Marketing, 13(1), 29-51.

Dabholkar, P. A., \& Spaid, B. I. (2012). Service failure and recovery in using technology-based self-service: effects on user attributions and satisfaction. Service Industries Journal, 32(9), 1415-1432.

Davis, F.D. (1989). Perceived usefulness, perceived ease of use, and user acceptance of information technology. MIS Quarterly, 13(3), 319-340.

Durkin, M. (2004). In search of the internet-banking customer: exploring the use of decision styles. International Journal of Bank Marketing, 22(7), 484-503.

Fishbein, M., \& Ajzen, I. (1975). Belief, Attitude, Intention and Behavior: An Introduction to Theory and Research. Reading, MA: Addison-Wesley Publishing Company.

Hoffman, D.L., Novak, T.P., \& Peralta, M. (1999). Building consumer trust online. Communications of the ACM, 42(4), 80-85.

Hyunsuk, I., Jung, J., Kim, Y., \& Shin, D-H. (2014). Factors affecting resistance and intention to use the smart tv. Journal of Media Business Studies, 11(3), 23-42.

Iyer, E.K., Unnikrishnan, S., Philip, P., \& Sundararajan, M. (2015). Extending technology adoption model by addition of cognitive 
Easwar Krishna Iyer et al Technology Adoption of Food Ordering Apps

inhibitors. Proceedings of International Conference on Business Management \& Information Systems, 89-95.

Joseph, R. C. (2010). Individual resistance to IT innovations. Communications of the ACM, 53(4), 144-146.

Laukkanen, T., Sinkkonen, S., Kivijärvi, M., \& Laukkanen, P. (2007). Innovation resistance among mature consumers. Journal of Consumer Marketing, 24(7), 419-427.

Lee, H.G. (1998). Do electronic marketplaces lower the price of goods?. Communications of the ACM, 41(1), 73-80.

Meuter, M.L., Ostrom, A.L., Bitner, M.J., \& Roundtree, R. (2003). The influence of technology anxiety on consumer use and experiences with self-service technologies. Journal of Business Research, 56(11), 899906.

Meuter, M. L., Ostrom, A. L., Roundtree, R. I., \& Bitner, M.J. (2000). Selfservice technologies: understanding customer satisfaction with technology based service encounters. Journal of Marketing, 64(3), 50-64.

Osgood, C. E., \& Tannenbaum, P. H. (1955). The principle of congruity in the prediction of attitude change. Psychological Review, 62(1), 42-55.

Parasuraman, A. (2000). Technology readiness index (TRI): a multiple item scale to measure readiness to embrace new technologies. Journal of Service Research, 2(4), 307-320.

Ram, S. (1987). A model of innovation resistance. Advances in Consumer Research, 14(1), 208-212.

Schnellbächer, C., Behr, J., Leonhäuser, I-U., \& Gießen. (2015). Potential of online food shopping: An opportunity to relieve mothers' everyday life food routines?. Ernahrungs Umschau, 62(11) 178-187.

Wakefield, R. L., Whitten, D. (2006). Mobile computing: a user study on hedonic/utilitarian mobile device usage. European Journal of Information Systems, 15(3), 292-300.

Shih, Y., \& Fang, K. (2006). Effects of network quality attributes on customer adoption intentions of Internet Banking. Total Quality Management \& Business Excellence, 17(1), 61-77. 
Appendix01 : Scales used for the study

\begin{tabular}{|c|c|c|}
\hline \multicolumn{3}{|r|}{ Qualifier } \\
\hline 1 & DV0 & I am a mobile app person \\
\hline & & Adoption \\
\hline 1 & DV & $\begin{array}{l}\text { I am happy with ordering food via phone cal and do not wish to switch to mobile } \\
\text { apps }\end{array}$ \\
\hline \multicolumn{3}{|r|}{ Insecurity } \\
\hline 1 & Insecurity1 & I am very cautious in trying mobile apps to order food online* \\
\hline 2 & Insecurity2 & I fear that if I order from a mobile app, I will not get exactly what I ordered \\
\hline 3 & Insecurity3 & $\begin{array}{l}\text { I feel that my food will not be packaged properly when ordered through mobile } \\
\text { app }\end{array}$ \\
\hline 4 & Insecurity 4 & I feel that I will not receive my order on time if I order it through a mobile app \\
\hline \multicolumn{3}{|r|}{ Infrastructure } \\
\hline 1 & Infra1 & I think that my order on a mobile app can fail due to a technical issue \\
\hline 1 & Infra2 & $\begin{array}{l}\text { I think my order may not go through due to poor internet connectivity or power } \\
\text { outage }\end{array}$ \\
\hline & $\begin{array}{l}\text { I think that an app crash will hamper my order } \\
\text { Discomfort }\end{array}$ \\
\hline 1 & Disconfort1 & I fear that technical skills are necessary for me to use mobile apps to order food \\
\hline 1 & Disconfort2 & $\begin{array}{l}\text { It may be embarrassing when people watch me struggle while ordering food via } \\
\text { mobile apps }\end{array}$ \\
\hline 1 & Disconfort3 & $\begin{array}{l}\text { It is not worthwhile learning to know how to order food from mobile apps } \\
\text { Inertia }\end{array}$ \\
\hline 1 & Inertia1 & $\begin{array}{l}\text { I would continue to order food via phone and other traditional means as I am } \\
\text { comfortable doing it }\end{array}$ \\
\hline 1 & Inertia2 & $\begin{array}{l}\text { I would stick to ordering food on the phone even through there are more efficient } \\
\text { ways to do it. }\end{array}$ \\
\hline 1 & Inertia3 & $\begin{array}{l}\text { I would continue ordering food on the phone as that is what I have always done } \\
\text { and see no reason to change it. }\end{array}$ \\
\hline
\end{tabular}

Italics marked in* Scale items dropped to improve Cronbach Alpha 